\title{
ANÁLISE DA FRAGMENTAÇÃO DA PAISAGEM NA REGIÃO EXTREMO OESTE PAULISTA, BRASIL
}

Carla Rodrigues Santos ${ }^{1}$ Paulo César Rocha²

Resumo: O conceito de estrutura da paisagem se refere ao estudo da paisagem a partir da medição e quantificação de seus aspectos estruturais e espaciais. $O$ objetivo deste artigo é avaliar as métricas da paisagem no extremo Oeste Paulista, Brasil. Para isso, usamos informações de imagens de satélite e um Sistema de Informação Geográfica, a fim de identificar o grau de retalhamento e isolamento da paisagem. Como resultados temos que a área é recoberta por usos antrópicos, que representavam $73,92 \%$, e o restante está distribuído em áreas naturais (área úmida, ilha e fragmentos florestais e corpos d'água). Ao analisarmos o índice de área, referente ao tamanho dos fragmentos, pudemos identificar que os maiores percentuais estão concentrados na pastagem $(42,51 \%)$ e agricultura $(28,58 \%)$. Os índices analisados confirmam que a fragmentação da paisagem é expressiva e sofre intensas perturbações.

Palavras-chave: Fragmentação da paisagem. Métrica da paisagem. Uso da terra. Sistema de Informação Geográfica. Oeste Paulista.

\section{LANDSCAPE FRAGMENTATION ANALYSIS OF THE IN THE WESTERN OF SÃO PAULO STATE, BRAZIL}

Abstract: The concept of landscape structure refers to the study of the landscape from the measurement and quantification of its structural and spatial aspects. The objective of this article is to evaluate the landscape metrics in the extreme western of São Paulo State, Brazil. For this, we used satellite image information and a Geographic Information System to identify the degree of landscape shredding and the isolation. As results, we verified that the area is covered by anthropic uses, which represented $73.92 \%$, and the rest is distributed in natural areas (wetland, island and forest fragments and water corpus). When analyzing the area index, referring to the size of the fragments, we could identify that the highest percentages are concentrated in pasture (42.51\%) and agriculture (28.58). The analyzed indexes confirm that the fragmentation of the landscape is expressive and undergoes intense perturbations.

Keywords: Landscape fragmentation. Landscape metrics. Land use. Geographic information system. West São Paulo.

\section{ANÁLISIS DE LA FRAGMENTACIÓN DEL PAISAJE EN LA REGIÓN DEL EXTREMO OESTE PAULISTA, BRASIL}

Resumen: El concepto de estructura del paisaje se refiere al estudio del paisaje a partir de la medición y cuantificación de sus aspectos estructurales y espaciales. El objetivo de este artículo es evaluar la estructura del paisaje en el extremo Oeste Paulista, Brasil. Para esto, utilizamos información de imágenes de satélite y un

\footnotetext{
${ }^{1}$ Universidade Estadual de Mato Grosso, Departamento de Geografia, Sinop, Brasil, carlageors@gmail.com.br, https://orcid.org/0000-0002-1075-889X

2 Universidade Estadual Paulista Júlio de Mesquita Filho, Departamento de Geografia, Presidente Prudente, Brasil, pcrochal@gmail.coml.br, https://orcid.org/0000-0002-1187-1093
} 
Sistema de Información Geográfica, a fin de identificar el grado de fragmentación y aislamiento del paisaje. Como resultados tenemos que el área está recubierta por usos antrópicos, que representaban el 73,92\%, y el resto está distribuido en áreas naturales (área húmeda, isla y fragmentos forestales y cuerpos de agua). Al analizar el índice de área, referente al tamaño de los fragmentos, pudimos identificar que los mayores porcentajes están concentrados en pastoreo $(42,51 \%)$ y agricultura $(28,58 \%)$. Los índices analizados confirman que la fragmentación del paisaje es expresiva y sufre intensas perturbaciones.

Palabras clave: Fragmentación del paisaje. Estructura del paisaje. Uso de la tierra. Sistema de Información Geográfica. Oeste Paulista.

\section{Introdução}

Os estudos da composição da paisagem e de seus respectivos arranjos espaciais mostram-se como reflexos gerados pela influência das mudanças históricas e modernas, nos âmbitos natural e antrópico (RICKLEFS, 2011). As paisagens são classificadas, segundo Dolfuss (1978) e Rodriguez et al. (2013), conforme o grau de intervenção antrópica, ou seja: paisagem natural é aquela que não teve nenhuma interferência humana; paisagem modificada é onde houve influência humana; e a paisagem cultural é onde se combinam a interferência contínua do homem e o ambiente. Estas últimas são consideradas também como paisagens rurais, caracterizadas pelas atividades agropastoris ou urbanas, formadas pela aglomeração humana.

Para Soares Filho (1998), ao analisar uma paisagem, seja ela natural, modificada ou cultural, devemos levar em consideração as diferentes escalas dos elementos da paisagem, os quais aparecem como manchas ou retalhos, variando em tamanho, forma, tipo, heterogeneidade e outras características. A estrutura da paisagem baseia-se numa matriz composta por um grupo de ecossistemas dominantes, contendo manchas ou fragmentos de outros ecossistemas, arranjados em padrões variáveis, conectados entre si ou isolados. As conexões entre os fragmentos são denominados corredores ecológicos, pois funcionam como meio de passagem entre um fragmento e outro (FORMAN, 1995; HOBBS, 1997; PUTZ et al., 2001).

Estudos realizados por Bierregaard et al. (1992) demonstram que os efeitos biológicos e físicos da fragmentação da paisagem podem ser mal compreendidos. Por isso, é essencial que se analise o tamanho dos fragmentos, a estabilidade e a capacidade de transporte de espécies, além do efeito de borda, para que se tenha uma noção dos fatores que afetam os fragmentos da paisagem. 
A observação, descrição e quantificação da estrutura da paisagem têm ajudado a identificar as mudanças ocorridas ao longo dos anos, as quais têm sido tomadas como objeto de estudo por vários pesquisadores, de diferentes áreas, entre elas, a Ecologia, a Geografia e a Biologia, a fim de diagnosticar o grau do retalhamento $e$ isolamento dos fragmentos florestais remanescentes (LANG e BLASCHKE, 2009).

O conceito de estrutura da paisagem visa à medição e quantificação de paisagens sob determinados aspectos estruturais e espaciais, com seus respectivos valores de medição, os quais denominamos medidas da estrutura da paisagem ou métricas da paisagem. Ao caracterizar tais medidas, deve-se levar em consideração os processos que atuam ou atuaram na determinação de suas mudanças estruturais (LANG \& BLASCHKE, 2009).

A obtenção de medidas da estrutura da paisagem ou métricas da paisagem tem permitido realizar avaliações em diferentes escalas espaciais e temporais, o que contribui significativamente para 0 entendimento dos padrões e processos envolvidos na manutenção de paisagens fragmentadas, e para estabelecer estratégias que visem à conservação da biodiversidade (ALMEIDA, 2008).

Nesse contexto, o objetivo do presente artigo foi avaliar as condições de retalhamento dos fragmentos de remanescentes florestais e o comportamento espacial da estrutura da paisagem do extremo oeste paulista, utilizando métricas de análise da paisagem, com intuito de identificar áreas propicias potenciais para criação de corredores ecológicos.

\section{Localização da área de estudo}

A área de estudo localiza-se na região Oeste de São Paulo, no entorno das bacias hidrográficas dos rios Paranapanema, Santo Anastácio, Aguapeí e do Peixe, abrangendo parcialmente as Unidades de Gerenciamento de Recursos Hídricos do Pontal do Paranapanema, do Peixe e do Aguapeí (UGRH 22, 21 e 20, respectivamente). Conforme a divisão hidrográfica do estado de São Paulo, definida pela Lei oํ 9.034/94, tais Unidades pertencem à bacia hidrográfica do rio Paraná, situada, aproximadamente, entre as coordenadas planas $346428 \mathrm{mE}-7559202 \mathrm{mN}$; $392360 \mathrm{mE}-7534097 \mathrm{mN}$; 474239mE - 7663046mN; e $429448 \mathrm{mE}-7691860 \mathrm{mN}$ (Figura 1). 
Figura 1 - Localização da área de estudo

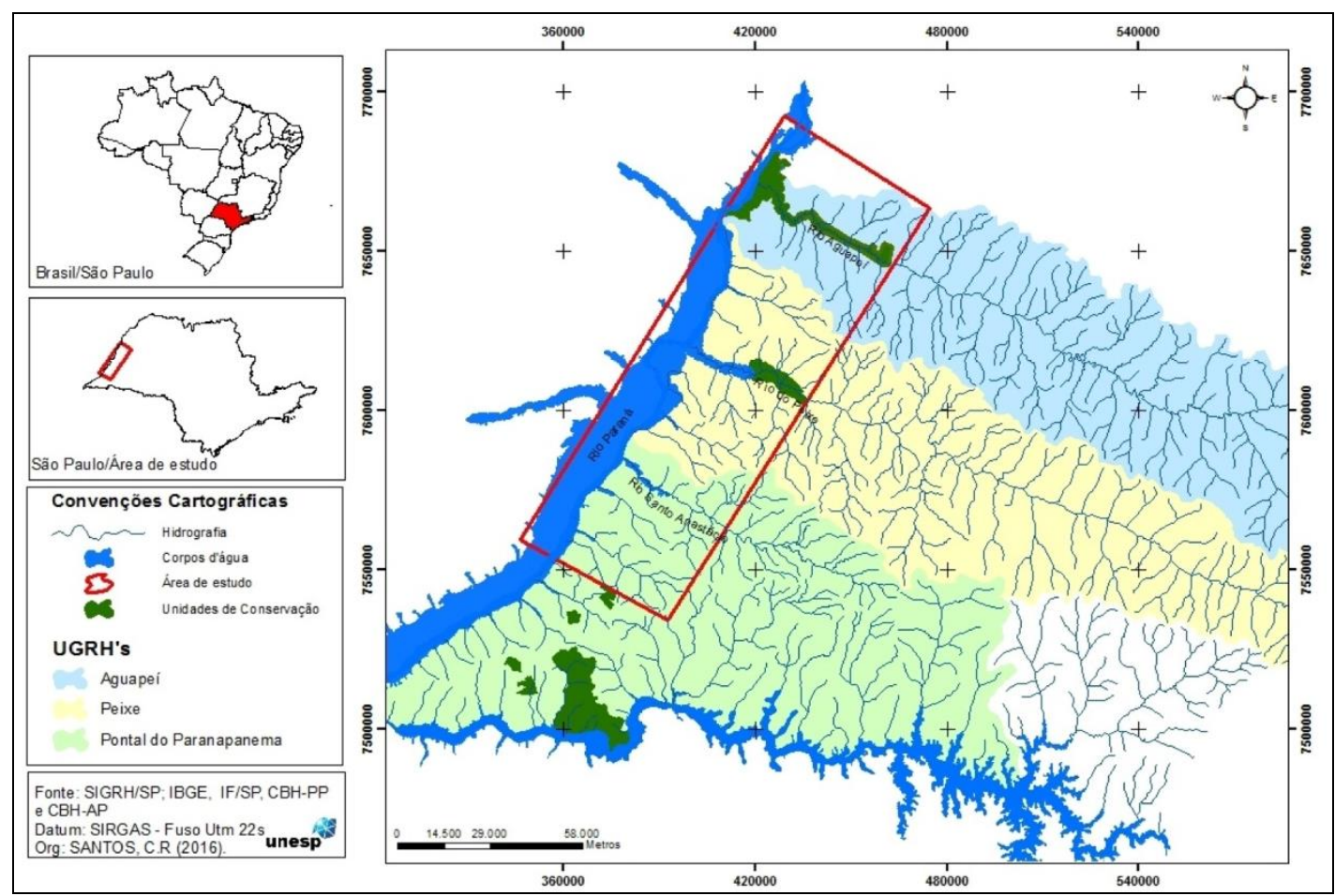

A formação geológica é constituída por rochas vulcânicas e predominantemente constituída de rochas sedimentares do Cretáceo do Grupo Bauru, destacando-se a Formação Caiuá, Formação Adamantina, Formação Santo Anastácio (IPT, 1981). A região é influenciada pela atuação das massas de ar tropical continental $(\mathrm{Tc})$, massa Equatorial Continental $(\mathrm{Ec})$ e massa tropical Atlântica (Ta), que influenciam na variação pluviométrica em torno de 1.100 e 1.500 $\mathrm{mm}$ anuais, alternando ciclos com temperaturas e índices pluviométricos mais elevados (de outubro a março) e ciclos com temperaturas e índices pluviométricos mais amenos (de abril a setembro) (SANT'ANNA NETO, 1995). Possui drenagem de rios consequentes e alinhados, que possuem certo paralelismo ao desaguarem no rio Paraná (ROSS e MOROZ, 1997).

O relevo é formado por colinas (relevo mais plano) e morrotes (relevo mais dissecado), sendo que na calha dos maiores rios ocorrem terraços e planícies de inundação ativas. Sendo que os municípios de Marília, Garça e Echaporã correspondem à região mais dissecada, constituída por formas erodidas, sustentadas pela Formação Marília (arenitos e conglomerados carbonáticos) $(\mathrm{CBH}-$ AP, 1997). Os solos dominantes são os Latossolos e Argissolos, oriundos da meteorização das rochas areníticas do Grupo Bauru (IPT, 1981). 
A vegetação da área de estudo é composta pela Floresta Estacional Semidecidual, inserida nos domínios da Mata Atlântica. Essa formação é condicionada por dupla estacionalidade climática (tropical e subtropical) e é constituída por fanerófitos com gemas foliares protegidas da seca por escamas (catáfilos ou pelos), cujas folhas adultas são esclerófilas ou membranáceas deciduais (IBGE, 2012).

\section{Fundamentação teórica}

\section{A estruturação da paisagem}

Estudos demonstram que a Ecologia da Paisagem foi a precursora na exploração de técnicas e métodos para avaliar a paisagem. A base da teoria iniciou com Humboldt (ZONNEVELD e FORMAN, 1989), mas seu conceito foi introduzido no final da década de 1930, por Carl Troll, um biogeógrafo alemão que conceituou o termo "Ecologia da paisagem" e que posteriormente foi denominada de Geoecologia. Forman e Godron (1986) afirma que o estudo do relacionamento espacial entre os elementos da paisagem são temas elencados na ecologia da paisagem e leva em consideração a estrutura horizontal da paisagem relacionada a distribuição dos objetos ecológicos. No entanto, a Geografia também possui um respaldo teórico e tecnicista nesse sentido, dispondo de métodos e técnicas favoráveis para tal avaliação. Ambas as ciências, portanto, são capazes de avaliar e testar sua metodologia quantitativa de análise espacial da paisagem.

O conceito de estrutura da paisagem visa à medição e quantificação de paisagens sob determinados aspectos estruturais e espaciais, com seus respectivos valores de medição, os quais denominamos medidas da estrutura da paisagem ou métricas da paisagem. Ao caracterizar tais medidas, deve-se levar em consideração os processos que atuam ou atuaram na determinação de suas mudanças estruturais (LANG \& BLASCHKE, 2009).

As várias formas de alteração no padrão espacial das paisagens resultam, predominantemente, das interações humanas, ou seja, derivam da extração de recursos naturais, do desenvolvimento de áreas agrícolas, da construção de cidades ou, ainda, da infraestrutura dos transportes (FORMAN \& GODRON, 1986), fatores que ocasionaram a fragmentação e, consequentemente, provocaram alterações no aumento das taxas de extinção, no ciclo hidrológico, na degradação do solo e no declínio da qualidade do hábitat humano (SOARES FILHO, 1998). A caracterização das estruturas da paisagem é elencada, segundo o conceito de, manchas, 
corredores e matriz, sendo as manchas os polígonos (patches), corredores (corridors) e matriz (matrix). A combinação desses elementos forma a variedade de mosaicos na terra, os quais são determinantes na caracterização ecológica ((FORMAN \& GODRON, 1986 apud CASIMIRO, 2002).

As manchas são comunidades de plantas ou de animais, constituindo um conjunto de espécies (CASIMIRO, 2002). "Contudo, algumas manchas podem não apresentar vida, ou conter somente microrganismos, sendo então caracterizadas mais proeminentemente pela presença, por exemplo, de rocha, solo, pavimento ou edifícios" (FORMAN \& GODRON, 1986, p.83).

Uma mancha (ou patch) é considerada uma área homogênea, não linear e que se diferencia da matriz na qual está inserida. Formam e Godron (1986) classificaram o estudo das manchas da paisagem em manchas de perturbação, manchas remanescentes, manchas de regeneração, manchas de recursos ambientais, manchas introduzidas e manchas efêmeras. Já Soares Filho (1998), definiu que existem quatro tipos de manchas que são definidas de acordo com suas origens ou mecanismos de atuação: manchas de perturbação, manchas remanescentes, manchas de distribuição de recursos ambientais e aquelas causadas pela alteração antrópica (CASIMIRO, 2002).

Segundo Ricklefs (2011), os corredores são faixas estreitas de hábitat que facilitam o movimento dos organismos entre os fragmentos adjacentes. Conectando as manchas de uma paisagem, propiciam o aumento de fluxo de genes e, consequentemente, da diversidade genética. No entanto, os corredores também podem facilitar o movimento de predadores, competidores e patógenos, em benefício de alguma espécie para conservação.

Os corredores de zonas ripárias, localizados ao longo de redes hidrológicas, atuam como zonas de amortecimento, realizando a filtragem de sedimentos, o controle de erosão, a regulação da temperatura e a manutenção da qualidade da água, a proteção do habitat de perturbações externas, o movimento de materiais e organismos e o fluxo de nutrientes (FORMAN, GODRON, 1986, p.146).

A figura 2 mostra a representação diagramática de um fluxo que ilustra quatro funções principais de um sistema articulado na paisagem. As zonas ribeirinhas e aquáticas fornecem um habitat para plantas e animais; fornecem caminho para o movimento de animais através do ambiente envolvente; representam uma barreira ou um filtro para os movimentos de certos animais e são uma fonte de travessia e interações com o ambiente circundante (BENNETT, 1990). 
Figura 2 - Diagrama de fluxo em zonas ripárias



Fonte: Bennett (2003, p.44)

A função dos corredores é fornecer recursos suficientes para sustentar a residência de um indivíduo ou uma população, a fim de manter a continuidade das populações entre os hábitats e a comunidade faunística, ao invés de apenas sustentar os movimentos frequentes dos indivíduos (BENNETT, 2003).

Segundo Forman \& Godron (1986), existem diferentes tipos de corredores ecológicos que possibilitam a composição e recomposição da qualidade do hábitat, cada um com sua origem específica: a) corredores de perturbação, como os rios associados à vegetação ripária, geralmente seguem os contornos topográficos e ambientais e são resultantes de processos naturais; b) corredores remanescentes, como fragmentos de floresta que não foram explorados dentro de uma área de desmatamento, ou de hábitats naturais mantidos como ligação entre reservas naturais; e c) corredores regeneração, resultantes de rebrota de uma faixa de vegetação que antes era limpa ou perturbada pela ação do homem.

Para Forman \& Godron (1986, p.205), a ocupação da paisagem deve ser planejada a partir dos conceitos espaciais de mancha, corredor e matriz. Importantes manchas de cobertura vegetal devem estar espacialmente conectadas, de modo a combater ou mitigar os efeitos da fragmentação.

Alguns padrões espaciais na paisagem são considerados fundamentais para a conservação ambiental. As grandes manchas de vegetação nativa e suas possíveis conexões, através dos corredores ao longo dos cursos d'água, aos fragmentos de vegetação nativa de menor qualidade ecológica são determinantes para entender as mudanças que ocorrem no padrão espacial natural da paisagem e no equilíbrio dos ecossistemas (FORMAN \& GODRON (1986).

A ligação entre os elementos de uma mesma classe estabelece, numa paisagem, um fator de conectividade estrutural, onde a interação entre as manchas, 
corredores e matriz se conectem numa configuração de rede, em que, os corredores permitem o movimento e intercâmbio genético de animais e plantas, enquanto as barreiras inibem tais trocas (SOARES FILHO, 1998, p.20). Diante disso, ao estudarmos os corredores, é necessário pensarmos na conectividade da paisagem, conforme Figura 3. A conectividade da paisagem pode ser conseguida de três formas principais: (a) através da gestão de todo o mosaico da paisagem, possibilitando a circulação; (b) trampolins de várias dimensões e espaçamentos; ou (c) corredores ecológicos que forneçam uma conexão contínua de habitat favorável. (BENNETT, 2003).

Figura 3 - Conectividade da paisagem



A conectividade dos fragmentos da paisagem pode ser representada em três escalas: a local (a menos de $1 \mathrm{~km}$ ); a paisagem (de $1 \mathrm{~km}$ a $10 \mathrm{~km}$ ); e a regional ou biogeográfica (de $100 \mathrm{~km}$ e $1.000 \mathrm{~km}$ ). Para que haja conexão entre espécies animais e processos ecológicos na escala de paisagem, um corredor adequado seria um rio com vasta vegetação ou uma ampla faixa delimitada para essa finalidade (BRIDGEWATER, 1987 apud BENNETT, 2003, p.60).

A compreensão do arranjo espacial e temporal da paisagem auxilia na identificação dos processos atuantes em determinado instante, além de possibilitar a reflexão dos processos determinantes no seu desenvolvimento, sejam eles físicos, ecológicos ou físico-ecológicos. Conforme Volotão (1998), a capacidade de quantificar a estrutura da paisagem é fundamental para o estudo das modificações 
dela, além de facilitar na compreensão de sua configuração, bem como da disposição das classes na paisagem.

\section{As métricas da paisagem}

A caracterização das métricas da paisagem visa identificar as origens ou os mecanismos causais das texturas ou padrões, para desenvolver modelos de paisagem (SOARES FILHO 1998, p.22). Diante disso, é necessário analisar a interação espacial e temporal dos padrões espaciais pelos métodos quantitativos.

Alguns autores que estudam a paisagem criaram métodos e índices que descrevem a configuração espacial da paisagem. Desses trabalhos, citamos os de Bowen \& Burgess (1981), Forman \& Godron (1986), Soares Filho (1998), Lang \& Blaschke (2009) Casimiro (2002), entre outros. A seguir, abordaremos algumas medidas da estrutura da paisagem.

\section{Métrica relativa a áreas}

A métrica relativa à área (patch) é considerada a medida da estrutura mais próxima da realidade e mais difundida entre os pesquisadores, e, por isso, talvez seja a mais importante, haja vista que muitas outras medidas são efetuadas direta ou indiretamente sobre ela (FORMAN \& GODRON, 1986). A área total de uma classe é calculada somando-se todas as áreas de manchas de uma determinada classe numa paisagem. O atributo espacial "área" possui uma grande importância na ecologia, principalmente quando relacionado com outros atributos (LANG \& BLASCHKE, 2009).

Para Bennett (2003), a área é um forte parâmetro para medir a diversidade de hábitats: a relação espécie-área indica que as áreas maiores abrigam mais espécies do que as menores. Argumenta, também, que os hábitats mais largos são benéficos no quesito espaço e na disponibilidade de alimentos para as espécies.

\section{Métrica relativa ao tamanho das manchas}

A área de cada mancha tem influência direta no nível de energia e troca de nutrientes disponíveis, além de determinar o fluxo de espécies (CASIMIRO, 2002). O índice de manchas indica a heterogeneidade de um hábitat e auxilia na determinação espacial do número de subpopulações dispersas. Quanto maior o número de manchas, maior será a resistência potencial à propagação de 
perturbações (doenças, fogo, entre outras); assim, podem as manchas persistir mais facilmente do que se o seu número fosse reduzido (CASIMIRO, 2002).

Segundo Odum (1983) e Soares Filho (1996), o tamanho das manchas determina a circulação de nutrientes, bem como a distribuição e quantidade de espécies na paisagem. A riqueza de espécies tem a tendência de diminuir à medida que a área do fragmento fica menor (FORMAN et al. 1976).

\section{Métrica relativa à forma}

De acordo com Casimiro (2002), a forma da mancha está diretamente relacionada ao efeito de margem, ou seja, quanto mais irregular, maior será a extensão de áreas de margem. As manchas alongadas são mais favoráveis para o funcionamento de corredores, pois abrigam maior diversidade no interior, e as manchas circulares, por sua vez, possuem maior diversidade de espécies e menos barreiras no seu interior (CASIMIRO, 2002).

O autor afirma que a forma das manchas se correlaciona à intensidade da ação antrópica, ou seja, quanto mais lineares e angulares são as margens, maior é a atuação da ação humana no elemento da paisagem. A Figura 4 apresenta alguns exemplos de formas naturais e antrópicas (CASIMIRO, 2002). .

Figura 4- Formas de manchas na paisagem, ordenadas por origem e forma.



FORMAN 1995, p.117 apud CASIMIRO, 2002a

Como se nota, as formas das manchas na paisagem são representadas em: a) Manchas naturais; e b) Manchas de origem humana (geométricas). Em A, temos: 1) Pântano; 2) Vertente em torno de um topo; 3) Perturbação no interior de uma mancha; 4) Delta; 5) Deslizamento, avalanche, mancha de floresta ao longo de curso de água; 6) Lago de origem glacial em forma de ferradura ou leito abandonado (duna barkan); 7) Área úmida; 8) Ilha num rio; 9)Manchas florestais ao longo de linha 
de água ou rio; 10) Topo com coada de lava; 11) Manchas florestais ao longo de rio com tributários; 12) Vegetação num topo estendendo-se pelas cumeadas adjacentes, perturbação por pisoteio de mamíferos em volta de um ponto de água; 13) Perturbação devida a incêndio; e 14) Povoação em torno de um poço. Em $B$, temos 15) Corte de um lote de árvores em florestas; 16) Manchas de árvores em terreno agrícola; 17) Padrões de uso e cobertura da terra em torno de uma localidade central; 18) Pequena barragem numa exploração agrícola; 19) Mancha de árvores em terreno agrícola; 21) Campo cultivado; 22) Pista de Esqui; 23) Campo cortado diagonalmente por estrada posterior; 24) Mancha de árvores na área de intersecção de várias explorações agrícolas; 25) Vila ou cidade em crescimento ao longo dos principais eixos de transporte; 26) Albufeira de uma barragem (FORMAN, 1995, p.117 apud CASIMIRO, 2002a).

O índice de forma, para Lang e Blaschke (2009, p.269), possibilita avaliar a complexidade da forma de uma mancha, por meio da comparação com uma feição padrão, ou seja, quanto mais a forma do elemento da paisagem se desviar do padrão redondo, maior será o valor do índice de forma.

\section{Métricas relativas a bordas}

A substituição de grandes áreas de vegetação natural por ecossistemas diferentes, como pastagens e agricultura, acarreta a criação de fragmentos isolados, inseridos numa matriz antrópica (FORMAN \& GODRON, 1986). Os fragmentos florestais formam uma borda que está diretamente em contato com a matriz antrópica, promovendo alterações nos parâmetros físicos, químicos e biológicos dos sistemas ambientais. São os chamados de "efeitos de borda" (WIENS et al. 1993; PRIMAK \& RODRIGUES, 2001).

Segundo Murcia (1995), os efeitos de borda podem ser divididos em abióticos, biológicos diretos e biológicos indiretos. Os primeiros envolvem mudanças ambientais onde a faixa de influência das bordas é mais exposta ao vento, às altas temperaturas, à baixa umidade e à alta radiação solar (REDDING et al., 2003). Já os efeitos biológicos diretos envolvem mudanças na distribuição de espécies provocadas pelos fatores abióticos nas proximidades das bordas. Os efeitos biológicos indiretos, por fim, compreendem alterações na forma de interação entre as espécies, tais como predação, parasitismo etc. (GALETTI, et al., 2003). 


\section{Dimensão fractal}

A dimensão fractal tem a função de medir a relação entre áreas interiores e áreas de borda das manchas, evidenciando a extensão dos hábitats ou ambientes de margem presentes em uma paisagem. Quanto mais extensas as áreas de margem, menor a resistência da paisagem a um evento de perturbação (SOARES FILHO, 1998).

Se a paisagem é composta por formas geométricas simples, como quadrados e retângulos, a dimensão fractal tende a ser pequena, aproximando-se de 1. Mas se a paisagem abriga muitos fragmentos de formas variadas e complexas, a dimensão fractal será grande (KRUMREEL et al., 1987).

\section{A quantificação da paisagem usando um Sistema de Informação Geográfica (SIG) e Sensoriamento Remoto}

Abordagens da Ecologia da Paisagem, com técnicas de sensoriamento remoto e uso do Sistema de Informação Geográfica (SIG), são necessárias quando o desafio é quantificar os mosaicos da paisagem no tempo e no espaço. A identificação das tendências dos padrões da paisagem fornece um conjunto de indicadores fundamentais para avaliar o status ecológico e as disposições em escalas variadas, admitindo comparações entre diferentes tipos de risco ecológico na paisagem, tais como erosão, prejuízo da produtividade do solo, perda da função hidrológica e da biodiversidade (JENSEN, 2011). Nesse sentido, o SIG auxilia na identificação dos parâmetros explicativos do uso da cobertura vegetal através de uma análise estatística (LANG e BLASCHKE, 2009).

As métricas de paisagem, associadas ao SIG e ao Sensoriamento Remoto no monitoramento da vegetação em manchas da paisagem, são componentes essenciais em avaliações de ecossistemas e têm sido bastante utilizadas em estudos ecológicos.

\section{Materiais e procedimentos metodológicos}

Para identificarmos o grau de retalhamento da paisagem, iremos quantificar a estrutura da paisagem ou métrica da paisagem por meio do Sistema de informação Geográfica.

\section{Materiais}

Para a realização deste trabalho recorremos a imagens Alos, sensor Avnir-2, com resolução de 10 m, composição colorida $2 R(0,52$ - 060 $\mu m) 4 R(0,76-0,89 \mu m)$ 
3B $(0,61-0,69 \mu \mathrm{m})$, conforme a figura 5 , de fevereiro de 2010 , adquiridas no laboratório de Gadis/Unesp - Presidente Prudente. As bases cartográficas foram adquiridas no site do Instituto Brasileiro de Geografia e Estatística (IBGE), e os dados das unidades de conservação, no Instituto Florestal de São Paulo. Todas as etapas de trabalho foram executadas nos softwares ArcGis 10.3 e Excel.

Figura 5 - Dados do satélite Alos, senosr Avnir-2

\begin{tabular}{|c|c|c|c|c|c|}
\hline Sensor & $\begin{array}{c}\text { Bandas } \\
\text { Espectrais }\end{array}$ & $\begin{array}{c}\text { Resolução } \\
\text { Espectral }\end{array}$ & $\begin{array}{c}\text { Resolução } \\
\text { Espacial }\end{array}$ & $\begin{array}{l}\text { Resolução } \\
\text { Radiométrica }\end{array}$ & $\begin{array}{c}\text { Área } \\
\text { Imageada }\end{array}$ \\
\hline \multirow{4}{*}{$\begin{array}{c}\text { AVNIR- } \\
2\end{array}$} & 1 & $0.42-0.50 \mu \mathrm{m}$ & \multirow{4}{*}{$10 \mathrm{~m}$} & \multirow{4}{*}{8 bits } & \multirow{4}{*}{$70 \mathrm{~km}$ (nadir) } \\
\hline & 2 & $0.52-0.60 \mu \mathrm{m}$ & & & \\
\hline & 3 & $0.61-0.69 \mu \mathrm{m}$ & & & \\
\hline & 4 & $0.76-0.89 \mu \mathrm{m}$ & & & \\
\hline
\end{tabular}

Fonte: https://www.cnpm.embrapa.br/projetos/sat/conteudo/missao_alos.html

\section{Procedimentos Metodológicos}

Para identificar o grau de retalhamento e o comportamento espacial da estrutura da paisagem da área pesquisada, realizou-se a composição colorida RGB, $2 \mathrm{R}(0,52-060 \mu \mathrm{m}) 4 \mathrm{R}(0,76-0,89 \mu \mathrm{m}) 3 \mathrm{~B}(0,61-0,69 \mu \mathrm{m})$ e elaborou-se 0 mosaico das imagens analisadas para unir as imagens referentes a área de estudo. Em seguida, foi realizada uma chave de fotointerpretação para identificação dos usos existentes na área pesquisada, conforme figura 6.

Figura 6 - Chave de fotointerpretação de uso e cobertura da terra de 2010

\begin{tabular}{|c|c|c|c|c|}
\hline Identificação topológica & Tonalidade & Textura & Forma & Amostra \\
\hline Água & escuro (azul ou preto) & liso & heterogênea & \\
\hline Área Úmida & escuro & liso & heterogênea & \\
\hline Ilha & escuro & rugoso & heterogênea & \\
\hline Vegetação & vermelho & rugoso & alveolar & \\
\hline Pastagem & claro & liso & retangular & \\
\hline Agricultura & vermelho claro e cian & liso & retangular & \\
\hline Silvicultura & vermelho escuro & rugoso & retangular & \\
\hline Mancha Urbana & cian claro & traçada heterogênea & quadriculada & \\
\hline
\end{tabular}

Org: do Autor (2016)

Posteriormente foi realizado à segmentação da imagem, a fim de separar e identificar as classes mapeadas. Para refinar o processo de mapeamento, foi utilizado também técnica de interpretação visual para abstrair as classes de uso e cobertura da terra. Para analisar o mapeamento realizado foi realizados trabalhos de 
campo, com o intuito de averiguar e validar as classes mapeadas. Os usos foram organizados nas seguintes classes: área úmida; ilha; fragmentos florestais; pastagem; agricultura; silvicultura; e mancha urbana.

Em seguida, quantificamos a área de cada fragmento florestal, a fim de comparar os tamanhos dos diversos fragmentos encontrados na área. Logo, foi realizado o cálculo das métricas da paisagem, através da extensão Patch Analyst, adaptada para o software ArcGis. Ela possibilita realizar análise espacial de fragmentos da paisagem, calculando o índice estatístico da estrutura da paisagem. As métricas obtidas são bastante utilizadas em estudos de Ecologia da Paisagem e Biogeografia, para tratar assuntos como área, densidade, tamanho, borda e forma (MCGARIGAL e MARKS, 1995; LANG \& BLASCHKE, 2009), conforme figura 7.

Em seguida, foram calculadas as métricas das manchas da paisagem, utilizando o Mapa de fragmentos florestais de 2010. Por fim, os dados foram organizados no Excel.

Figura 7 - Índices de Ecologia da Paisagem utilizados para identificar os fragmentos da paisagem, gerados no Patch Analyst.

\begin{tabular}{|c|c|c|c|}
\hline $\begin{array}{l}\text { Estrutura da } \\
\text { paisagem }\end{array}$ & Métrica (unidade) & $\begin{array}{c}\text { Siglas } \\
\text { em } \\
\text { Inglês }\end{array}$ & Definição \\
\hline Métricas de Área & Área de todas as manchas da Classe (ha) & $\mathrm{CA}$ & $\begin{array}{l}\text { Área de todos os fragmentos } \\
\text { de cada classe }\end{array}$ \\
\hline \multirow{4}{*}{$\begin{array}{c}\text { Métricas de } \\
\text { Densidade, Tamanho } \\
\text { e Variabilidade }\end{array}$} & Tamanho médio da mancha dos fragmentos ha) & MPS & $\begin{array}{l}\text { Média aritmética do tamanho } \\
\text { de todos os fragmentos de } \\
\text { cada classe }\end{array}$ \\
\hline & Número de manchas dos fragmentos & NUMP & Número total de fragmentos \\
\hline & $\begin{array}{l}\text { Desvio padrão do Tamanho das manchas dos } \\
\text { Fragmentos (ha) }\end{array}$ & PSSD & $\begin{array}{l}\text { Desvio padrão de todos os } \\
\text { tamanhos de fragmentos de } \\
\text { cada classe }\end{array}$ \\
\hline & Coeficiente de variação do tamanho da mancha & PSCoV & $\begin{array}{l}\text { Desvio Padrão do tamanho da } \\
\text { mancha dividido pelo } \\
\text { tamanho médio da mancha, } \\
\text { multiplicado por } 100\end{array}$ \\
\hline \multirow[b]{2}{*}{ Métricas de Borda } & Total de Bordas da Paisagem (m) & $\mathrm{TE}$ & $\begin{array}{l}\text { Extensão total das bordas da } \\
\text { paisagem }\end{array}$ \\
\hline & Densidade das Bordas (m/ha) & ED & $\begin{array}{l}\text { Densidade do total de bordas } \\
\text { de cada classe em relação à } \\
\text { área total }\end{array}$ \\
\hline \multirow{3}{*}{ Métricas de Forma } & Índice de Forma & MSI & $\begin{array}{l}\text { Médias das formas dos } \\
\text { fragmentos da paisagem }\end{array}$ \\
\hline & Índice Média ponderada de Forma & AWMSI & $\begin{array}{l}\text { Média ponderada das classes } \\
\text { pela área total }\end{array}$ \\
\hline & Dimensão fractal da mancha média & MPFD & $\begin{array}{l}\text { Os valores se aproximam de } 1 \\
\text { para formas de perímetros } \\
\text { simples e } 2 \text { para as formas } \\
\text { mais complexas }\end{array}$ \\
\hline
\end{tabular}

Fonte: Adaptado de McGarigal \& Marks, 1995; Lang \& Blascke, 2009

Org: do Autor. (2016). 


\section{Resultados e discussões}

A análise das mudanças na estrutura da paisagem aqui apresentada serviu como base para entendermos o processo de ocupação da área estudada, permitindo identificar o grau de retalhamento e o comportamento espacial da estrutura da paisagem, através dos índices de Ecologia da Paisagem. Os resultados mostram que a área pesquisada dispõe de $10,43 \%$ fragmentos florestais representados por manchas de floresta estacionária semidecidual e vegetação de várzea e ilhas. Entretanto, as métricas indicam que existe um alto grau de retalhamento da paisagem, que somando-as tem-se um total de 6.601 manchas com tamanhos e formas variadas, as quais sofrem efeito de borda, comprometendo assim sua qualidade (tabela 1).

A maior parte do extremo Oeste paulista $(73,92 \%)$ é recoberta por usos antrópicos (pastagem, agricultura, silvicultura e mancha urbana) no ano de 2010, enquanto o restante da superfície é composta por área úmida, ilha, fragmentos florestais e corpos d'água.

Esses valores da distribuição espacial permitem inferir que as áreas antrópicas estão distribuídas de forma contínua, caracterizando-se como uma matriz. Por outro lado, as áreas naturais estão mais próximas às planícies de inundação ou a córregos d'água, constituindo as patches: manchas de fragmentos da paisagem.

Existem algumas manchas de fragmentos florestais espalhadas ao longo de todo o extremo Oeste paulista, mas a maioria se encontra disposta perto ou dentro das Unidades de Conservação (UCs) do Parque Estadual Aguapeí e Peixe e da Reserva Particular do Patrimônio Natural do Aguapeí, localizadas nas planícies de inundação (Figura 8). 
Figura 8 - Matriz antrópica com presença de fragmentos florestais no entorno dos Parques Estaduais do Aguapeí e Rio do Peixe, respectivamente.


A - Foz do Rio Aguapeí

B - Foz do rio do Peixe

Org. do autor (2017)

Os índices da estrutura da paisagem apresentados na tabela 1 permitem avaliar as condições dos fragmentos em relação à distribuição espacial no ano de 2010.

Tabela 1 - Cálculo do índice de Ecologia da Paisagem para as classes de uso e cobertura da terra de 2010

\begin{tabular}{|c|c|c|c|c|c|c|c|c|c|c|c|}
\hline \multirow{2}{*}{$\begin{array}{c}\text { Estrutura } \\
\text { da } \\
\text { paisagem }\end{array}$} & \multirow{2}{*}{ Índice } & \multirow{2}{*}{ Unidade } & \multicolumn{8}{|c|}{ Uso e cobertura da terra - 2010} & \multirow[b]{2}{*}{$\begin{array}{c}\text { Todas as } \\
\text { Classes }\end{array}$} \\
\hline & & & Água & Área úmida & Ilha & $\begin{array}{c}\text { Fragmentos } \\
\text { florestais }\end{array}$ & Pastagem & Agricultura & Silvicultura & \begin{tabular}{|c|} 
Mancha \\
Urbana
\end{tabular} & \\
\hline Área & $\mathrm{CA}$ & Hectares (ha) & 128353,77 & 37022,30 & 3795,94 & 42850,81 & 348589,74 & 234339,39 & 1040,54 & 6183,16 & 802175,65 \\
\hline \multirow{4}{*}{$\begin{array}{l}\text { Densidade } \\
\text { e tamanho }\end{array}$} & MPS 2010 & Hectares (ha) & 573,01 & 29,74 & 632,66 & 8,91 & 755,78 & 350,53 & 74,32 & 229,01 & 110,73 \\
\hline & NUMP & Adimensional & 224,00 & 1245 & 6 & 4810 & 448 & 640 & 14 & 27 & 7416,00 \\
\hline & PSSD 2010 & Hectares (ha) & 4804,77 & 115,73 & 960,67 & 54,09 & 2477,13 & 874,36 & 153,04 & 386,62 & 1145,02 \\
\hline & PSCoV 2010 & Porcentagem & 838,52 & 389,17 & 151,85 & 607,12 & 327,76 & 249,44 & 205,90 & 168,82 & 1034,09 \\
\hline \multirow{2}{*}{ Borda } & $\mathrm{TE}$ & Metros (m) & 1428303,20 & 5824554,65 & 70606,56 & 5978520,73 & 8550207,60 & 5677129,76 & 48395,46 & 188037,43 & 28069857,58 \\
\hline & ED & $\mathrm{m} / \mathrm{ha}$ & 1,74 & 7,09 & 0,09 & 7,28 & 10,41 & 6,91 & 0,06 & 0,23 & 34,18 \\
\hline \multirow{3}{*}{ Forma } & MSI-2010 & Adimensional & 2,47 & 2,66 & 1,74 & 1,53 & 2,17 & 1,65 & 1,46 & 1,47 & 1,79 \\
\hline & AWMSI-2010 & Adimensional & 2,18 & 4,76 & 1,55 & 3,49 & 4,13 & 2,27 & 1,49 & 1,91 & 3,23 \\
\hline & MPFD-2010 & Adimensional & 1,38 & 1,52 & 1,25 & 1,38 & 1,32 & 1,27 & 1,26 & 1,24 & 1,39 \\
\hline
\end{tabular}

CA (Área de todas as manchas da classe); MPS (Tamanho médio da mancha); NumP (Número de manchas); PSSD (Desvio padrão do tamanho da mancha); PScoV (Coeficiente de variação do tamanho da mancha); TE (Total de bordas); ED (Densidade de Borda); MSI (Índice de forma médio); AWMSI (Índice de forma de área média ponderada) e MPFD (Dimensão fractal da mancha média).

Ao analisar o índice CA (Figura 9), que informa o tamanho das classes, podemos identificar que, em 2010, os maiores percentuais estão concentrados na pastagem $(42,51 \%)$, seguidos pela agricultura $(28,58 \%)$ e pelos fragmentos florestais $(5,23 \%)$. 
Figura 9 - Índice de área de todas as manchas da paisagem de uso e cobertura da terra de 2010

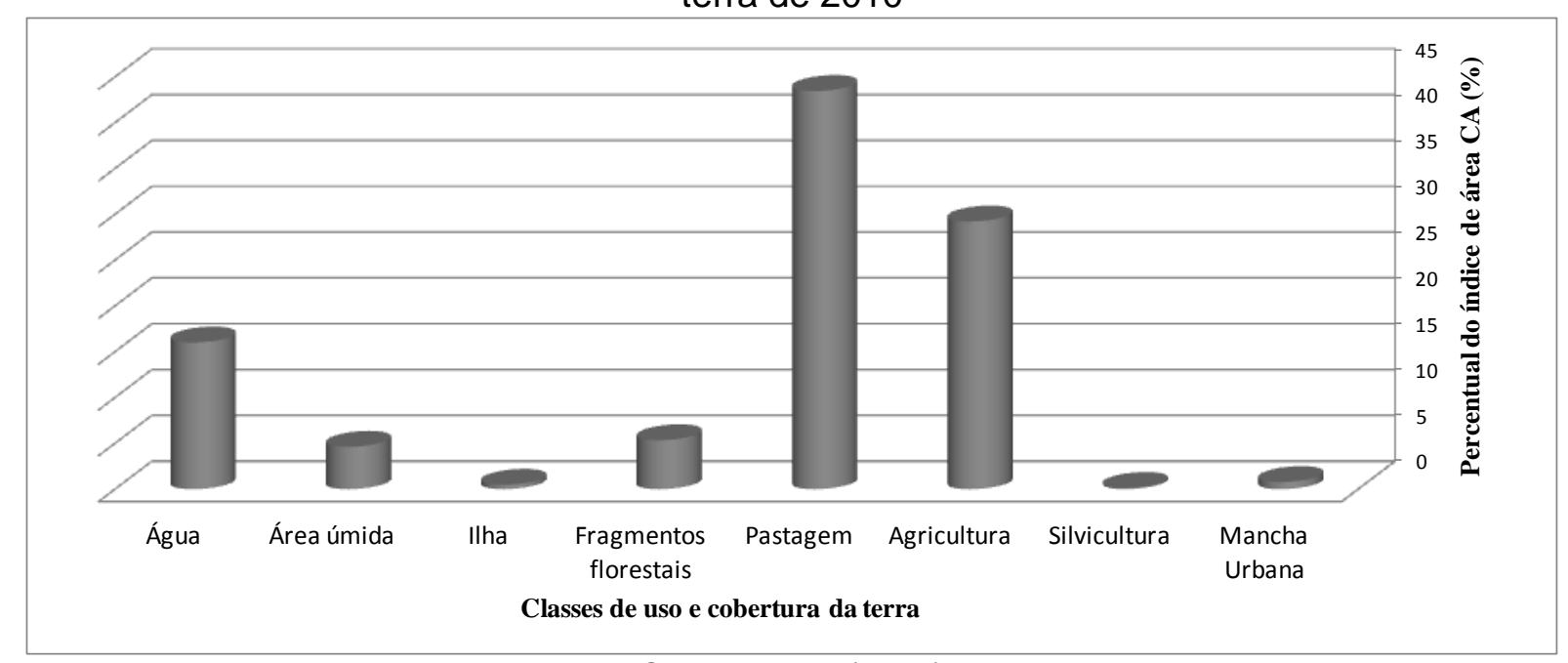

Org. do autor (2016)

De acordo com Pinto et al. (2005), quando a pastagem é bem manejada, pode oferecer proteção do solo durante o ano todo, ao contrário das culturas agrícolas, que expõem o solo na época do plantio. A pastagem só passa a ser problema quando uma matriz circundante é exposta a práticas inadequadas de manejo, como compactação do solo, superpastejo e grandes áreas de solo exposto (PINTO et al., 2005).

Em 2010, os fragmentos florestais apresentavam-se rodeados, em grande parte, por áreas agrícolas, principalmente por plantações de cana-de-açúcar. Essas áreas sofreram processos intensos de modificação (solo exposto, plantio, colheita), que afetaram diretamente a proteção do solo.

Ao analisar cada classe separadamente (Figura 10), podemos verificar que 0 tamanho médio das manchas (MPS) é maior na classe de pastagem (755,78 ha), ao passo que o tamanho médio das manchas para fragmentos florestais é de 8,91 ha, com um grande número de manchas pequenas, indicando que o ambiente passou por um processo de supressão vegetacional. 
Figura 10 - Índice do tamanho médio das manchas e coeficiente da variação do tamanho das manchas na paisagem de uso e cobertura da terra de 2010.



Org do autor. (2016)

As métricas de bordas (Tabela 1) estão relacionadas ao perímetro/área do fragmento: o índice TE refere-se à densidade do total de bordas e o índice ED, à densidade do total de bordas em relação à área total, mostrando, assim, o grau de retalhamento do ambiente. No ano analisado, ressalte-se que o TE mede 28.069.857,58 $\mathrm{m}$ e o ED, 34,18 m/ha, reforçando a tese de que a paisagem da região do Oeste paulista passa por um processo intenso de fragmentação e sofre perturbações externas, principalmente quando se nota um índice de 10,41 m/ha ED para pastagem.

Ao analisar o índice ED da figura 11 para as categorias fragmentos florestais e áreas úmidas, temos 7,28 m/ha (ED) e 7,09m/ha (ED), respectivamente. Segundo Valente e Vettorzzi (2002), a ampliação do efeito de borda tende a diminuir proporcionalmente à área dos fragmentos, o que influenciará na qualidade da estrutura desses ecossistemas. 
Figura 11 - Índice de densidade de borda na paisagem de uso e cobertura da terra de 2010.

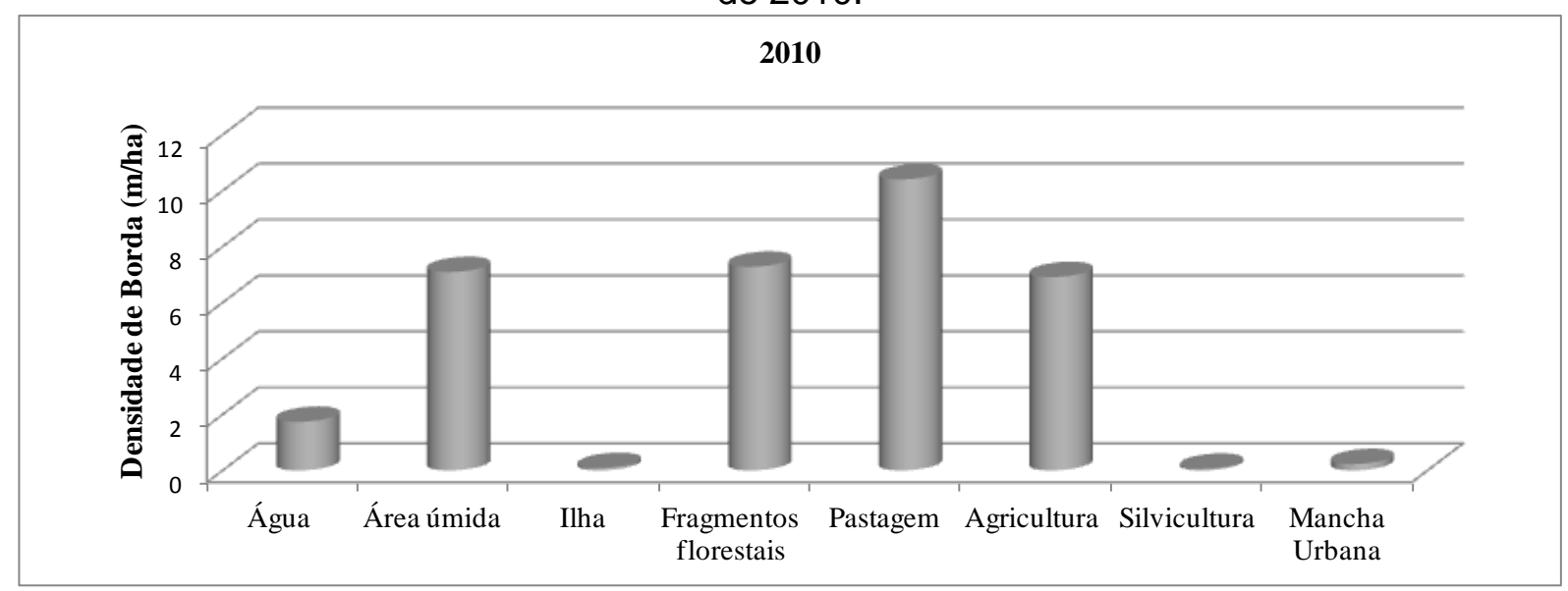

Org: do autor (2016)

O índice de forma médio (MSI) e o índice de forma de área média ponderada (AWMSI) mostram como os fragmentos estão distribuídos na paisagem e, quanto mais próximos de 1, menor é a complexidade da forma (PIRES, 1995). Diante disso, ao analisar o índice de forma MSI, da figura 12, percebe-se que as classes áreas úmidas e fragmentos florestais apresentam um alto índice de forma médio, com 2,66 e 1,53, respectivamente. Para a categoria áreas úmidas, o índice analisado indica uma fragmentação com formatos irregulares; no entanto, o índice de fragmentos florestais diminui, fazendo com que os contornos dos fragmentos passem de irregulares para formas mais simples, tendendo para circulares.

Figura 12 - Índices de Forma das manchas da paisagem de uso e cobertura da terra de 2010.

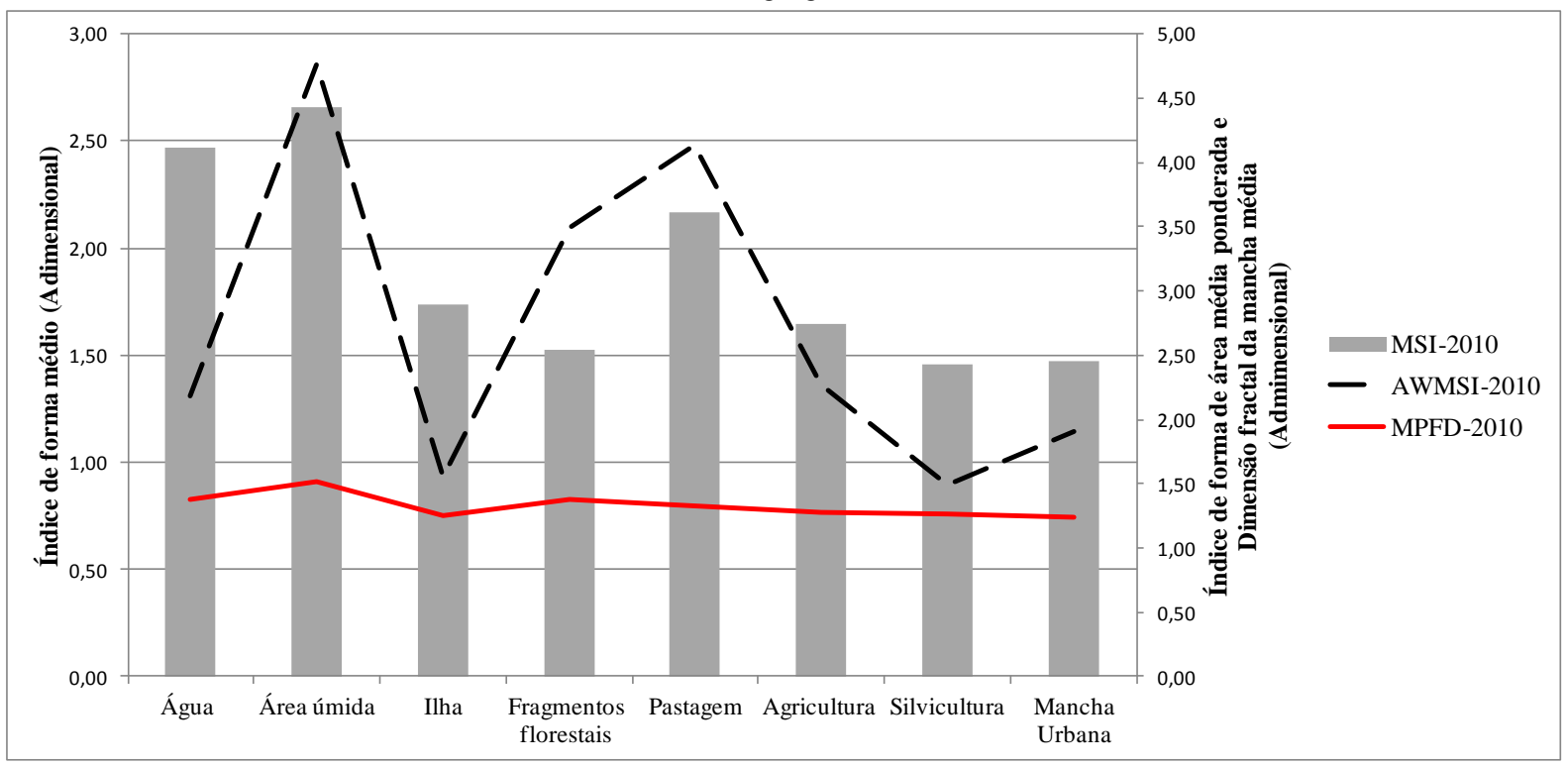

Org: do autor (2016)

O padrão alongado e linear formado por vegetação rasteira, com resquícios de Floresta Estacionaria semidecidual, é um ambiente favorável à formação de 
corredores ecológicos, além de contribuir para a troca de fluxo genético entre os fragmentos maiores, a proteção dos cursos d'água, na manutenção das cheias e vazantes, e para a redução dos processos erosivos. A dimensão fractal (MPFD) indica que os formatos se tornaram mais irregulares. $\mathrm{Na}$ área escolhida para estudo, é evidente que as manchas da paisagem se mostram pouco irregulares, pois apresentam valores muito próximos de $1, \mathrm{e}$ isso se vale para todas as classes, como se pode visualizar na figura 12. Em paisagem altamente fragmentada, muitas vezes a dimensão fractal pode não ser aplicável para determinar a forma de florestas remanescentes, devido ao limiar de amplitude (1-2), que torna essa dimensão menos sensível a variações que o índice de forma MSI, segundo Mcgarigal \& Marks (1995).

A Figura 13 mostra os tipos de manchas encontradas na paisagem. $\mathrm{Na}$ amostra 1, identificam-se manchas naturais, como áreas úmidas e manchas florestais ao longo de linhas de água ou rios. Na amostra 2, verifica-se um ambiente modificado, com ocorrência simultânea de fragmentos florestais e outras atividades de uso da terra (pastagem e agricultura).

Figura 13 - Formas das manchas na paisagem na área de estudo.

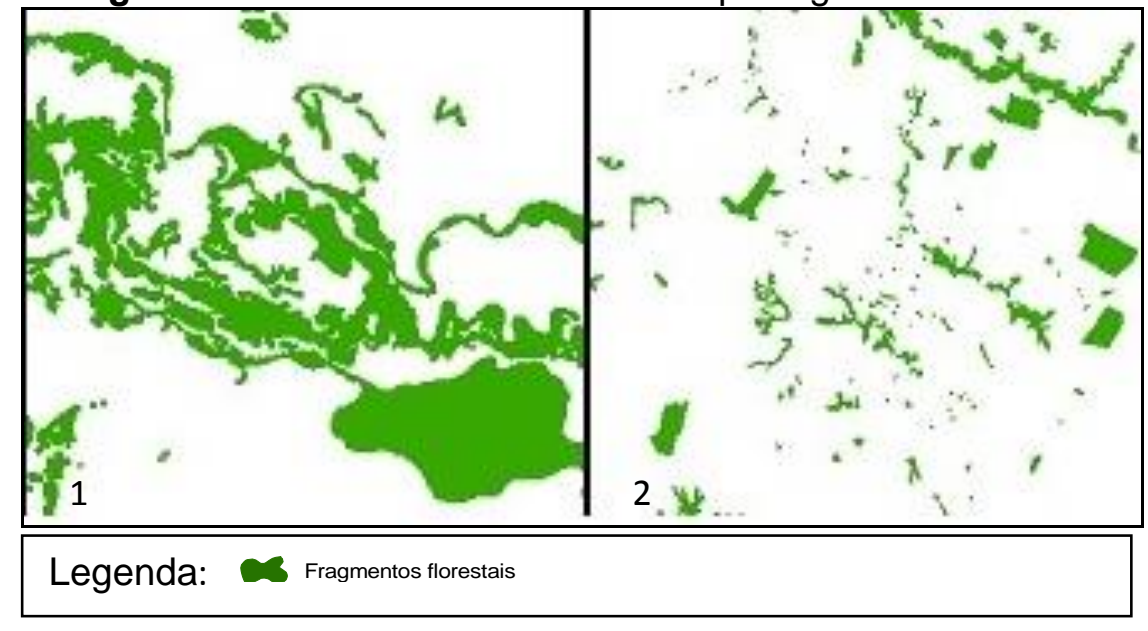

Amostra 1

Amostra 2

Amostra 1 - Manchas em áreas úmidas e Mata ciliares ao longo de linhas de água ou rios. Amostra 2- Manchas de fragmentos florestais circundados pelas atividades agrícolas e pecuária.

Org do autor (2016)

Uma das alternativas para minimizar ou inibir o grau de retalhamento da paisagem seria com a expansão das áreas de fragmentos disponíveis através da integração dos fragmentos florestais utilizando corredores ecológicos. Pois as áreas maiores têm uma capacidade também maior de reter riquezas de espécies e manter processos ecológicos naturais (FORMAN, 1995). 
Outra possibilidade seria fazer o controle racional dos usos da terra, principalmente da pastagem e da monocultura, evitando, assim, o desequilíbrio do ambiente, melhorando assim a qualidade dos hábitats (BENNETT, 2003).

\section{Considerações}

Concluímos que são notáveis as transformações ocorridas no estremo Oeste Paulista. Os índices analisados confirmam que a fragmentação da paisagem é expressiva, o desmatamento ao longo dos anos de ocupação da área propiciou a formação de um ambiente modificado, que sofre perturbações ocasionadas pelo sistema agropastoril.

Os resultados mostram que a área pesquisada dispõem de 10,43\% de fragmentos florestais, constituídos de Floresta Estacional Semidecidual, vegetação de várzea e ilhas. A área é recoberta por $73,92 \%$ de usos antrópicos (pastagem, agricultura, silvicultura e mancha urbana).

Os índices de métrica da paisagem indicam que as áreas com maiores manchas estão localizados na agricultura e pastagem e que o tamanho médio das manchas também prevalece nas classes de pastagem, enquanto os fragmentos florestais possuem apenas $8,91 \%$, com um alto índice de manchas pequenas. As classes de áreas úmidas e fragmentos florestais apresentam um alto índice de forma médio, com 2,66 e 1,53, com fragmentos com formatos irregulares.

Num ambiente fortemente degradado ou desmatado, é mais difícil escolher os melhores locais para estabelecer a conectividade dos fragmentos. Mas a opção dessa conectividade existe, reforçando a ideia de novas estratégias de conservação para propiciar a vida selvagem, os mananciais e a qualidade hídrica. Isso é possível através da proteção e infiltração da água no solo e do fornecimento de nutrientes essenciais, que controlam e contribuem para as cadeias alimentares aquáticas.

O planejamento é essencial na integração da paisagem, pois um dos desafios de hoje é conciliar a conservação da natureza e os múltiplos usos da terra. Uma possível estratégia de conservação para as áreas agrícolas seria a conexão entre os fragmentos florestais, com reservas de conservação combinadas a conexões de matas ciliares, a fim de ligar as áreas menores de todo o hábitat circulado por terras agrícolas.

A metodologia dos índices de estrutura da paisagem, com utilização do SIG e de técnicas de sensoriamento remoto, auxiliaram na compreensão e na análise da 
área de estudo. Essas técnicas podem ajudar a entender as condições ambientais e suas implicações ecológicas em nível local e regional.

\section{REFÊRENCIAS}

ALMEIDA, C. G. Análise espacial dos fragmentos florestais na área do Parque Nacional dos Campos Gerais, Paraná/PR. 72 f. Dissertação (Mestrado em Gestão do território), Universidade Estadual de Ponta Grossa, Paraná, 2008.

BENNETT, A. F. Habitat Corridors: Their Role in Wildlife Management and Conservation. (Department of Conservation and Environment: Melbourne/AUS. 1990

BENNETT, A. F. Linkages in the landscape. The role of corridors and connectivity in Wildlife Conservation. IUCN The World Conservation Union, 2003.In: http://www2.ecolex.org/server2.php/libcat/docs/LI/MON-080215.pdf. Acessado em 24 ago., 2015.

BIERREGAARD, R. O., LOVEJOY, T. E., KAPOS, V., SANTOS, A. A.; HUTCHINGS, W. The biological dynamics of tropical rainforest fragments. In: BioSciences, n. 42, p. 859-866, 1992. Disponível em: http://www2.ecolex.org/server2.php/libcat/docs/LI/MON-080215.pdf. Acesso em: 26 jan. 2013

BOWEN, G. W. e BURGESS, R. L., 1981. A quantitative analysis of forest island pattern in selected Ohio landscapes. Knoxville, ORNL Environmental Sciences Division, ORNTUTM-7759.

BRIDGEWATER, P.B. Connectivity: an Australian perspective. pp. 195-200 In: Nature Conservation: The Role of Remnants of Native Vegetation.. New South Wales, 1987.

CASIMIRO, P.C. Uso do Solo, Teledetecção e Ecologia da Paisagem - Ensaio

Metodológico, Conselho de Mértola. Tese de Doutoramento, Lisboa/PT, DGPR - FCSH UNL, 585 p. 2002

CASIMIRO, P.C. Uso do Solo - Ecologia da Paisagem: Quantificação da Estrutura da Paisagem para Análise de Padrões Espaciais - Concelho de Mértola. In: Revista Geolnova - Revista do Departamento de Geografia e Planeamento Regional, № 4 - 2002, F.C.S.H. - U.N.L., pp. 125-157, 2002a

$\mathrm{CBH}-\mathrm{AP}$. Comitê das bacias hidrográficas dos rios Aguapeí e Peixe. Relatório de Situação dos recursos hídricos das UGRHIs 20 e 21, 1997. Disponível em: htt://cbhap.org/publicacoes/relatorioz p /. Acessado em 4.abr.2013.

DOLFFUS, O. O espaço geográfico. 3ed. São Paulo, Difel, 1978

FIQUEIRÓ, A. Biogeografia: dinâmicas e transformações da natureza. São Paulo, Oficina de Textos, 2015.

FORMAN, R. T. T. Land mosaics: the ecology of landscape end regions. In: Cambridge University Press. 1995. 632p. Disponível em: <www.fundaj.gov.br/rtec/res/res-001.html>. Acesso em: 30 out. 2011.

FORMAN, R.; GODRON, M. Landscape Ecology. Nova lorque, EUA, John Wiley \& Sons. 1986. 619p. 
GALETTI, M.; ALVES-COSTA, C.P. \& CAZETTA, E. Effects of forest fragmentation, anthropogenic edges and fruit color on the consumption of ornithocoric fruits. In: Biological Conservation 111: 269-273, 2003

HOBBS, R. Future landscape and the future of landscape ecology. Landscape and Urban Planning. v.37, n.1-2, p. 1-9, June 1997

HOBBS, R.J. Effects of landscape fragmentation on ecosystem processes in the Western Australian wheatbelt. Biological Conservation 64. 1993.p.193-201.

IBGE. Instituto Brasileiro de Geografia e Estatística. Manual Técnico da Vegetação Brasileira: sistema fitogeográfico, inventário de formações florestais e campestres, técnicas e manejo de coleções botânicas, procedimentos para mapeamentos. Rio de Janeiro: Ministério do Planejamento, Orçamento e Gestão, 2012.

IPT - INSTITUTO DE PESQUISAS TECNOLÓGICAS. Mapa geomorfológico do Estado de São Paulo. Escala: 1:1.000.000. São Paulo: IPT, 1981.

JENSEN, J.R. Sensoriamento remoto do ambiente. Uma perspectiva em recursos terrestres. São José dos Campos, $2^{\underline{a}}$ edição, SP. 2011

KRUMMEL, J.R., GARDNER, R.H., SUGIHARA, G., O'NEILL, R.V. AND COLEMAN, P.R. Landscape pattern in a disturbed environment. Oikos 48: 321-324.1987

LANG, S. \& T. BLASCHKE. Análise da Paisagem com SIG. Tradução Hermann Kux. São Paulo. Oficina de Textos, p.423, 2009.

MCGARIGAL AND MARKS. Fragstats: Spatial pattern analysis program for quantify in glandscape structure. Portland (OR): USDA Forest Service, Pacific Northwest Research Station; General Technical Report PNW-GTR-351. 59 p.1995.

MURCIA, C. Edge effects in fragmented forests: implications for conservation. In: Ecology and Evolution 10: 58-62. 1995.

ODUM, H.T. Systems ecology. New York, Wiley Interscience, 1983.

O'NEILL, R.V., HUNSAKER, C.T., JONES, K.B., RIITTERS, K.H., WICKHAM, J.D., PINTO, L.V.A.; FERREIRA, E.; BOTELHO, S.A.; DAVIDE, A.C. Caracterização física da bacia hidrográfica do ribeirão Santa Cruz, Lavras, MG e uso conflitante da terra em suas áreas de preservação permanente. Cerne, Lavras, v.11, p.49-60, jan./mar. 2005.

PIRES, J. S. R. Análise Ambiental voltada ao Planejamento e Gerenciamento do Ambiente Rural: Abordagem Metodológica aplicada ao Município de Luiz Antônio SP. 1995. 166 f.Tese (Doutorado)-Universidade Federal de São Carlos, São Carlos/SP, 1995. Disponível em: http://www.lapa.ufscar.br/pdf/tese_jose_salatiel_r_pires_1995.pdf. Acessado em 4 out. 2014.

PRIMAK, R.B. \& RODRIGUES, E. In: Biologia da Conservação. Londrina, Midiograf. 2001

PUTZ, F. E.; BLATE, G. M.; REDFORD, K. H.; FIMBEL, R.; ROBINSON, J. Tropical forest management and conservation of biodiversity: an overview. In: Conservation Biology, v. 15, n. 1, p. 7-20, Feb. 2001.

REDDING, T.E.; HOPE, G.D.; FORTIN, M.J.; SCHMIDT, M.G. \& BAILEY, W.G. Spatial patterns of soil temperature and moisture across subalpine forest-clearcut edges in the southern interior of British Columbia. Canadian Journal of Soil Science 83: 121-130, 2003 
RICKLEFS, R.E. A economia da Natureza. Tradutor: Pedro P. de Lima e Silva. Rio de Janeiro, 2011. p.546.

RODRIGUEZ, J. M. M.; SILVA, E. V.; CAVALCANTI, A. P. B. Geoecologia das paisagens: Uma visão geossistêmica da análise ambiental. 4.ed. Edições UFC, Fortaleza/CE, 2013.

ROSS, J. L. S.; MOROZ, I.C. Mapa geomorfológico do Estado de São Paulo. 1:500.000 Vol. I - Mapa - Vol II - Livro. São Paulo: FAPESP, 1997, v.1. São Paulo: FAPESP, 1997. v. 1. $66 p$.

SANT'ANNA NETO, J.L. As chuvas no Estado de São Paulo: contribuição ao estudo da variabilidade e tendência da pluviosidade na perspectiva da análise geográfica. São Paulo, 1995. (Doctoral Thesis in Physical Geography) - Universidade de São Paulo

SOARES FILHO, B.S.S. Análise de paisagem: fragmentacão e mudanças. Departamento de Cartografia, Centro de Sensoriamento Remoto . Instituto de Geociências, UFMG. 1998. In: http://csr.ufmg.br/dinamica utils/download/files/publications/apostila.pdf. Acessado em abril 2013

TROLL, C. (1966). Landscape Ecology. Delf: Publ. UNESCO, 23p.

VALENTE, R. O. A.; VETTORAZZI, C. A. Análise da estrutura da paisagem na Bacia do Rio Corumbataí. Scientia Florestalis, Piracicaba/SP, n. 62, p. 114-119, 2002.

VOLOTÃO, C.F. DE SÁ. Trabalho de análise espacial: Métricas do Fragstats. INPE, São José dos Campos, São Paulo - SP, 1998 . Disponível em:

http://www.dpi.inpe.br/cursos/ser431/trabalhos/fragstats.pdf. Acessado em: 8 out. 2014.

WIENS, J.A.; STENSETH, N.C.; VAN HORNE, B. \& IMS, R.A. 1993. Ecological mechanisms and landscape ecology. Oikos 66: 369-380.

ZONNEVELD I.S.; FORMAN, R.T.T. eds. Changing Landscapes: In: Ecological Perspective. Spinger-Verlag. 1989, p.20. Disponível em: http://www.edc.uri.edu. Acesso em: 23 abr.2016.

\section{NOTAS DE AUTOR}

\section{CONTRIBUIÇÃO DE AUTORIA}

Carla Rodrigues Santos - Concepção e elaboração do manuscrito. Coleta de dados, Análise de dados, Elaboração do manuscrito, revisão e aprovação da versão final do trabalho

Paulo César Rocha - Participação ativa da discussão dos resultados. Revisão e aprovação da versão final do trabalho.

\section{FINANCIAMENTO}

Os autores agradem ao órgão de fomento CNPq pelo apoio financeiro inscritos no processo 167704/2014-1

\section{CONSENTIMENTO DE USO DE IMAGEM}

Não se aplica

APROVAÇÃO DE COMITÊ DE ÉTICA EM PESQUISA

Não se aplica

\section{CONFLITO DE INTERESSES}

Não se aplica adaptar, criar para qualquer fim, desde que atribua a autoria da obra. 
HISTÓRICO

Recebido em: 24-08-2017

Aprovado em: 15-04-2019 